\title{
Ouvir vozes: um estudo netnográfico de ambientes virtuais para ajuda mútua
}

\section{| ${ }^{1}$ Octávia Cristina Barros, ${ }^{2}$ Octavio Domont de Serpa Jr I}

Resumo: O artigo tem como foco de reflexão a formação de uma rede social constituída através de uma mídia social da internet, a Intervoice, buscando compreender de que forma as redes sociais se integram em ofertas de ajuda mútua. Ao escolhermos como eixo de nossa abordagem a experiência vivida por ouvidores de vozes em ambientes virtuais da Intervoice, buscamos identificar a existência de uma mudança de perspectiva em relação às abordagens tradicionais da psiquiatria no que concerne ao cuidado oferecido, no sentido mais amplo, ao seu público-alvo, bem como analisar se essa mídia social favorece o processo de ajuda mútua para pessoas que ouvem vozes. Desenvolvemos uma metodologia a partir da observação das postagens da Intervoice no Facebook, de setembro de 2014 a maio de 2015. Após análise minuciosa, identificamos que o Facebook foi a mídia mais utilizada se comparada ao Twitter e YouTube. Recortamos os posts e comentários mais interessantes e pontuamos assuntos e discussôes específicas, sobretudo as que tratavam de ajuda mútua. Os resultados apontam para a extrema relevância que a ajuda mútua vem ganhando nos últimos tempos, através de ambientes virtuais e redes sociais, sobretudo pela possibilidade de interação em tempo real.

> Palavras-chave: ouvidores de vozes; ajuda mútua; mídia e redes sociais.

\footnotetext{
${ }^{1}$ Instituto de Psiquiatria

Universidade Federal do Rio de Janeiro. Rio de Janeiro-RJ, Brasil (octaviacristinabarros@ gmail.com).

2 Instituto de Psiquiatria, Universidade Federal do Rio de Janeiro. Rio de Janeiro-RJ, Brasil (domserpa@gmail.com).
} 
Ouvir vozes costuma ser uma experiência perturbadora, que muitas vezes perdura por um longo tempo, apesar dos esforços terapêuticos. Como qualquer experiência perturbadora, provoca a busca de um entendimento que lhe dê sentido. Sob o olhar da Psiquiatria tradicional, a medicalização é a primeira opção na tentativa de eliminar as vozes. Para Romme e Escher (1997), continuamos reféns de uma prática que produz doentes crônicos, lança à margem do sistema pessoas com sofrimento psíquico, e entende a própria reabilitação psiquiátrica mais como uma forma de tornar o "doente mental" menos doente do que como um processo de maximizar suas potencialidades e inseri-las no convívio social, livres de qualquer estigma.

No final da década de 1980, como resultado do trabalho de Marius Romme e Sandra Escher, foi criada na Holanda a Intervoice (The International Network for Training, Education and Research into Hearing Voices), uma organização cuja proposta é oferecer suporte administrativo e coordenar uma série de iniciativas destinadas a promover o emprego de novas abordagens no cuidado dos ouvidores de vozes, partindo do princípio de que o problema principal náo é o fato de ouvir vozes, mas a dificuldade de estabelecer algum tipo de convivência com elas. A partir de 2007, a Intervoice passou a atuar no ambiente virtual e o acesso dos ouvidores de vozes ao grupo foi ampliado (http://www.intervoiceonline.org/).

Esta pesquisa tem como foco de reflexão a formaçáo de uma rede social constituída através de uma mídia social da internet, a Intervoice, buscando compreender de que forma as mesmas se integram em ofertas de ajuda mútua. Pretende-se analisar de que modo a interação entre pessoas que ouvem vozes e o compartilhamento de suas vivências de ouvir vozes promove ajuda mútua quando essas pessoas utilizam o ambiente virtual da Intervoice.

A metodologia utilizada para esta pesquisa seguiu a perspectiva qualitativa e empregou o método da netnografia. Após observarmos as narrativas de pessoas que ouvem vozes através de postagens disponibilizadas pelas mídias sociais da Intervoice, constatamos que os usuários da Intervoice concentram suas interaçóes no Facebook. Durante nove meses, observamos 793 postagens na mídia social Intervoice do Facebook sobre assuntos diversos, como artigos sobre doenças mentais, tratamentos, esquizofrenia, depressão, prevenção de suicídio, transtorno bipolar, psicose pós-parto, meditação, divulgação de congressos, 
artigos sobre terapia espiritual, hipnose, postagens de imagens, documentários sobre esquizofrenia e medicamentos.

Para este artigo, elencamos postagens do grupo Intervoice no Facebook que tratam especificamente da experiência de ouvir vozes. Agrupamos as postagens e os comentários semelhantes em relação ao seu conteúdo, para entendermos o compartilhamento das experiências dos ouvidores de vozes e como se processa a busca por novas abordagens do fenômeno.

\section{Construindo um novo olhar: outras abordagens sobre o fenômeno "ouvir vozes"}

De acordo com Serpa Júnior (2013), a alucinação auditiva verbal deveria ser entendida como mais propriamente referida à linguagem ou ao controle das próprias ações, e não à sensopercepção. Este entendimento dá importantes pistas clínicas, sugerindo que criar condições para que o sujeito ouvidor de vozes possa se apropriar das suas experiências alucinatórias, ressignificando-as, pode ser um caminho para transformar o caráter frequentemente doloroso e alienante.

Coleman (2011) relata que enquanto a psiquiatria tradicional enfatiza a erradicação e supressão das vozes, o movimento dos ouvidores de vozes oferece uma abordagem alternativa que valoriza a audição de vozes como significativa e originada dentro do contexto da história de vida da pessoa, favorecendo a procura por caminhos positivos para se comunicar com elas. Romme e Escher (1997) afirmam que o primeiro e fundamental passo é aceitar as vozes como fazendo parte de si mesmo. Para Corstens et al. (2008), a psiquiatria, frequentemente, destitui a audição de vozes como um fenômeno patológico sem sentido, com nenhuma relevância para as circunstâncias emocionais ou sociais de um indivíduo e, desta forma, os profissionais da área são geralmente encorajados a não se engajarem com as experiências de audição de vozes de seus clientes.

Para Hal Stone e Sidra Stone (1993), uma abordagem eficaz consiste em conversar com as vozes, reforçando a relação entre as vozes e os ouvidores de vozes. Nessa abordagem, há uma tentativa de explorar os motivos das mesmas, para que a pessoa possa encontrar novas estratégias para lidar com as vozes. Este método objetiva melhorar a relação entre os ouvidores e as vozes, ajudando a pessoa a gerar estratégias e técnicas positivas para lidar melhor com sua experiência. 
Outro método interessante para abordar o fenômeno "ouvir vozes" é o do Diálogo Aberto, que consiste em trabalhar com as pessoas que são diagnosticadas com esquizofrenia e outras formas de psicose (que apresentam o fenômeno da audição de vozes), oferecendo uma forma diferente para as pessoas que vivem uma crise mental e seus familiares. Esta abordagem foi desenvolvida nos últimos 30 anos, na Finlândia, por Sekkula, Sutela e a equipe multidisciplinar do Hospital Keropudas (SEKKULA; OLSON, 2003).

O objetivo do método é estabelecer um diálogo aberto entre todos os envolvidos numa situação de crise, propondo apoio imediato no prazo de 24 horas após o contato inicial. Foca-se a atenção em ajudar a melhorar as relaçôes sociais que cercam a pessoa em crise como a chave para a recuperação, abordando os problemas na rede social a partir de esclarecimentos acerca de mudanças de atitudes, as quais não se concentram apenas na pessoa que está em crise (SEKKULA; OLSON, 2003).

A comunicação é uma maneira de transpor as barreiras do isolamento, sendo primordial na troca de opiniôes e de informaçóes. Baseados nessa premissa, Romme e Escher fundaram, no final da década de 80, na Holanda, um movimento em defesa do emprego de novas abordagens baseadas na troca de experiência entre os ouvidores de vozes (ROMME; ESCHER, 1997).

Em 1987 foi criado o The Hearing Voices Movement, também por Romme e Escher. Esse movimento defende o emprego de novas técnicas, utilizadas por aqueles que enfrentaram positivamente as vozes. Para promoção e discussão da temática, foi criada uma organização formal que oferece suporte administrativo e coordena a ampla variedade de iniciativas em diversos países. Essa organização, chamada de Intervoice, atua como um órgão de coordenação internacional, dirigido por um Conselho constituído por pessoas que ouvem vozes, por peritos de profissão e pelo Movimento Internacional de Ouvidores de Vozes.

O Movimento Internacional de Ouvidores de Vozes detectou que muitas pessoas que ouvem vozes ainda não estáo incomodadas por elas ou encontraram suas próprias maneiras de lidar com as vozes fora da assistência psiquiátrica. Isso é muito significativo, mostrando que as pessoas que ouvem vozes continuam saudáveis. No entanto, há também um número significativo de ouvidores de vozes que são esmagados pelos aspectos negativos e incapacitantes da experiência, a qual impede que algumas pessoas vivam uma vida plena na sociedade e pode 
levar a ter uma qualidade de vida muito ruim. Procura-se permitir que ouvidores

de vozes incomodados com sua experiência mudem seu relacionamento e atitude com suas vozes e retomem suas vidas. A intenção é garantir que esta abordagem inovadora seja mais conhecida por profissionais, familiares e amigos.

Atualmente, estima-se que mais de 80 países façam parte da comunidade internacional de ouvidores de vozes. A crescente adesão de países à Intervoice e a The Hearing Voices Network aponta a importância do desenvolvimento de novas abordagens para a temática do fenômeno "ouvir vozes".

\section{Alguém pode ouvir as minhas vozes?}

Os grupos de ajuda mútua inserem-se num significativo, e em expansão, movimento social contemporâneo. Como movimento social, assenta-se no respeito pela diversidade das pessoas, acredita nas capacidades individuais e da comunidade, na voluntariedade dos náo profissionais, visa ao fortalecimento de suas potencialidades e identifica ou cria os recursos para apoiar as pessoas em necessidade (RAPPAPORT, 1990). A primeira experiência deste tipo surgiu nos Estados Unidos, em 1935, com a criação dos Alcoólicos Anônimos (NEWTON, 1984), inaugurando uma série crescente que tem incluído outros grupos anônimos, inclusive aqueles identificados com dependência emocional/afetiva/ sexual (SILVA, 2008; PEIXOTO; HEILBORN, 2016).

O processo de ajuda mútua concretiza-se através da ação dos grupos de parceiros que partilham uma situação de vida através da qual se identificam e fundamenta-se na vivência subjetiva dos problemas de cada um dos membros, isto é, no conhecimento da experiência (BOORKMAN, 1991). Segundo Presotto et al. (2013), diante das complexas questôes da emoção, da dor, do desespero, da angústia moral e da perda do sentido de vida associadas ao transtorno mental, o enfrentamento desses dilemas e desafios concretos do cotidiano com o sofrimento psíquico, através dos grupos de ajuda mútua, valoriza e promove a troca de experiência acumulada pelos usuários e seus familiares.

A ajuda mútua visa primordialmente à acolhida, à troca de experiências e de apoio emocional, realizadas em grupos compostos, na medida do possível, por pessoas com problemas comuns, que partilham do mesmo tipo de sofrimento (VASCONCELOS, 2013). Para Romme e Escher (1997) os membros dos grupos de ouvidores de vozes ganham confiança, encontram apoio, aprendem a lidar 
com as vozes, aprendem a conhecer a si mesmo com a ajuda dos outros, tomam conhecimento da grande variedade de experiências individuais e aprendem a falar de seus problemas com familiares e amigos. A troca entre os membros diminui a ansiedade e aumenta a autonomia. Além dos grupos presenciais, as estratégias de ajuda mútua estão presentes hoje também na internet.

\section{Internet e Intervoice: outras possibilidades através das mídias sociais}

Recuero (2009) afirma que, na atualidade, as tecnologias digitais tornaram-se palco para grandes discussóes e transformaçóes nos cenários políticos, culturais, econômicos e de comunicação, oportunizando o conhecimento e o estudo da sociedade e de suas relaçóes, salientando a relevância das tecnologias digitais na composição das redes sociais na internet. Redes sociais são pessoas interagindo, por qualquer meio, mediadas ou não por sistemas digitais (FRANCO, 2013). Mídias sociais são meios como o Twitter, o Facebook, o YouTube, sites de relacionamento, serviços de emissão e troca de mensagens, entre outros. Todos esses meios são plataformas que utilizamos para nos comunicarmos, passando informaçôes para as pessoas (FRANCO, 2009).

Melca et al. (2014) compreendem que a internet, através das mídias sociais, vem se consolidando como um ambiente de infinitas possibilidades de interação entre as pessoas, as quais estão se valendo desses meios tecnológicos como forma de modificar suas condiçóes de pessoas com patologias para agentes da sua própria saúde.

Os usuários de uma mídia social geralmente compartilham algo em comum - pessoal ou profissional - com os demais membros da rede, com convivência apenas no espaço virtual ou também no espaço real. Mas o cerne dessas conexóes é que as pessoas escolhem participar de redes que agrupam pessoas de hábitos, características ou condições semelhantes às suas.

Em 2007, foi criado o site Intervoice, de acesso público, com o objetivo de ofertar um lugar seguro para os ouvidores de vozes, buscando criar uma comunidade online interativa, proporcionar troca de experiências, e formas de superar as dificuldades enfrentadas pelas pessoas que ouvem vozes, destacando os aspectos mais positivos da experiência e sua importância cultural e histórica. Uma das metas da Intervoice é mudar a forma que a sociedade considera a experiência de ouvir vozes. 
A Intervoice foi registrada no Twitter em 19 de março de 2010 (https://twitter. com/VoicesUnLtd), com a característica de uma comunidade internacional cujo objetivo é divulgar o trabalho sobre a experiência de ouvir vozes. O Twitter da Intervoice tem como principal finalidade a publicidade, um contato mais dinâmico com seus usuários, mas não é u ma ferramenta de discussão, pois não fornece uma boa plataforma para isso, visto que as postagens não são agrupadas de forma a serem lidas sequencialmente, o que dificulta a interação mais dinâmica. Até 15 de maio de 2015, a Intervoice reuniu 3.116 seguidores.

Em 2009, foi criado o grupo Intervoice no Facebook (http://www.facebook. com/groups/intervoice/), que chegou a 5.099 membros em 15 de maio de 2015. Com fórum aberto para discussões, apoio, conselhos e informação sobre escutar vozes, é destinado a qualquer um com interesse: ouvidores de vozes, familiares, amigos e profissionais da área.

Em 2011, a Intervoice criou um canal no YouTube, que permite que bilhóes de pessoas descubram, assistam e compartilhem vídeos. Até 15 de maio de 2015, o canal possuía 378 inscritos, e tinha alcançado cerca de 20.075 exibiçốes de seus 13 vídeos próprios. (https://www.youtube.com/user/v01ce5000).

O grupo Intervoice no Facebook é um grupo público, não uma página ou perfil. O conteúdo das postagens é de acesso público, porém a associação ao grupo é feita através da solicitação do usuário, que tem que ter uma conta no Facebook. Grupos são comunidades para os membros participantes se conhecerem e conversarem sobre interesses comuns, são espaços compartilhados. Grupos abertos como este aparecem nos resultados de pesquisa no Facebook ou em ferramentas de busca tipo Google.

Neste grupo do Facebook, somente membros podem postar. Considerando que cada um provavelmente sofreu exclusóes, estigmas e traumas, o interesse dos participantes é, geralmente, em relatos de experiências e contato com novas perspectivas e, sobretudo, na possibilidade de compartilhar ideias e notícias acerca do assunto. As discussóes de forma mais estrita não são moderadas, mas os posts de insulto e ataque são sempre removidos por conta de uma regra que visa manter o diálogo salutar entre os membros. A proposta é que todos pensem sobre os posts e tratem as pessoas com dignidade.

As pessoas sempre se relacionaram em redes, mas com o advento da internet foram apresentadas a novos modos de interagir, que as aproximam com maior 
rapidez, permitindo estabelecer laços sociais com um número maior de pessoas, independentemente de sua localização geográfica. Assim, as ferramentas da web podem ser grandes aliadas, tanto na exposição de informaçôes quanto proporcionando espaços colaborativos e interativos entre as pessoas, que tendem a servir-se dos espaços digitais para buscar informaçóes sobre doenças, expor seus sentimentos e experiências com o processo de adoecimento e compartilhar suas angústias e sofrimentos com outros que também estão vivenciando algo parecido (CRUZ et al., 2011).

Como veremos adiante, as postagens selecionadas para este estudo evidenciaram o sofrimento psíquico, a sensação de exclusão social e a busca de estratégias de superação pelos ouvidores de vozes. Isso nos leva ao estudo de Muñoz et al. (2011), que trata das narrativas individuais que têm sido consideradas de extrema importância no campo da saúde mental, a fim de propiciar às pessoas que vivenciam a psicose a participação em discussóes sobre os recursos, elaboraçáo e planejamento de estratégias que lhes permita minimizar e conviver com seu sofrimento.

Além do grupo do Facebook, há uma série de fóruns de ajuda/discussão relacionados a este movimento, incluindo o fórum Hearing Voices: (http:// www.mentalhealthforum.net/forum/forumdisplay.php?99-Hearing-Voices) e o Fórum em inglês (www.hvn.forumatic.com) da Hearing Voices Network. Os fóruns de discussão são ferramentas para páginas de internet destinadas a promover debates através de mensagens publicadas abordando uma mesma questão. Portanto, as mídias sociais da Intervoice são um lugar especial para contribuiçóes tanto dos ouvidores quanto de outras pessoas que desejem compartilhar suas opinióes e diferenças.

Todos os fóruns de ajuda/discussão abordados nesta pesquisa são em inglês. As esparsas iniciativas brasileiras no trabalho alternativo com ouvidores de vozes se aproximaram do Intervoice muito recentemente, e só durante esta pesquisa foi criado, em 21 de maio de 2015, pelos autores deste artigo, um grupo público no Facebook: Intervoice: Movimento Internacional de Ouvidores de Vozes/Brasil (https://www.facebook.com/groups/intervoicebrasil/), que tem como objetivo facilitar o acesso, a informação e o desenvolvimento de troca de experiências, no ambiente virtual, tanto dos ouvidores de vozes, quanto de profissionais, familiares e simpatizantes do tema no Brasil. 
As dificuldades encontradas pelas pessoas em nosso país, que não possuem o domínio da língua inglesa, podem ser minimizadas através do acesso a esse grupo público, baseado na mesma proposta do grupo Intervoice, bem como o acesso ao grupo Ouvir Vozes Coimbra (https://www.facebook.com/ouvirvozescoimbrapt/), criado em 18 de janeiro de 2016, em Portugal, com o objetivo de validar as experiências e percepçóes dos ouvidores de vozes e implicá-los na implementação de estratégias de ajuda mútua.

\section{Métodos}

O presente estudo visou observar as interações e narrativas das pessoas que ouvem vozes nas mídias sociais da Intervoice, durante nove meses (setembro de 2014 a maio de 2015). Na primeira etapa, foram realizadas observação e análise nas mídias, a fim de obter informaçóes de relevância para a pesquisa. Foram observadas postagens disponibilizadas nos sites de redes sociais da Intervoice: Twitter, YouTube e Facebook. Entretanto, as interaçóes via Twitter e YouTube não se mostraram suficientemente relevantes, visto que, atualmente, os usuários da Intervoice concentram suas interaçôes no Facebook. Das mídias sociais investigadas, o Facebook é a que atinge maior número de pessoas, expõe mais informações e cria mais discussões, na medida em que proporciona maior interação entre os usuários. Por isso, o elegemos como a mídia social para observaçâo e análise dos dados da pesquisa.

$\mathrm{Na}$ segunda etapa, foram transcritas as interaçóes observadas entre os ouvidores de vozes do grupo do Facebook. E na última etapa algumas postagens foram agrupadas por temas, cujos conteúdos expressam experiências pessoais e interaçóes com outros ouvidores de vozes conectados no grupo, na perspectiva da ajuda mútua, a partir da troca de experiências.

Adotamos como método a netnografia, adaptação do método etnográfico para os ambientes online, que permite um estudo detalhado das relaçôes nos espaços virtuais, nos quais a internet é a interface cotidiana da vida das pessoas e lugar de encontro que permite a formação de comunidades, grupos estáveis e a emergência de novas formas de sociabilidade (TURKLE, 1997). Com o surgimento das comunidades virtuais, essa vertente metodológica começou a ser amplamente estudada (HINE, 2000, 2005; KOZINETS, 2002, 2007). Segundo Kozinets (2002), a netnografia apresenta vantagens, como consumir menos tempo, ser menos dispendiosa e menos subjetiva, além de ser menos invasiva, já 
que o olhar do pesquisador sobre os comportamentos de uma comunidade pode ser equiparado a uma janela, fora do espaço fabricado para a pesquisa.

Desenvolvemos a presente pesquisa baseados no pesquisador silencioso, segundo a tipologia que considera dois tipos extremos de pesquisadores na rede em termos de seu grau de inserção: o silencioso (lurker) e o insider (FRAGOSO; RECUERO; AMARAL, 2011). O pesquisador silencioso é aquele que apenas observa determinado grupo social, uma prática denominada lurking, que em inglês significa "ficar à espreita” (BRAGA, 2006), objetivando interferir o mínimo possível em suas práticas cotidianas (sabe-se que uma não interferência em grau absoluta não é possível, tendo em vista que sua presença, ainda que não anunciada, afetará o objeto de estudo). Já o insider é o oposto, pois ou está inserido nos grupos sociais e/ou mantém ligações próximas com o objetivo de estudo.

O grupo Intervoice do Facebook - Intervoice: The International Hearing Voices Movement é um grupo público, portanto as postagens são públicas e acessíveis a todos que são usuários do Facebook. Para a observação, não nos apresentamos à comunidade como pesquisadores. Durante o processo de coleta de dados da pesquisa, observávamos os posts e comentários que tratavam especificamente da forma como as pessoas lidavam com o fenômeno "ouvir vozes". A única pessoa com quem interagimos virtualmente nesse processo foi o moderador do grupo, Paul Baker.

Os usuários que participam do grupo estudado são pessoas que ouvem vozes e buscam identificação com seus pares. Partilham da mesma experiência, passando por um processo de estigmatização, isolamento e estranheza, necessitando compreender sua condição peculiar de estar no mundo. Utilizam o grupo como uma ferramenta que permite aumentar a autoconfiança, oferendo uma rede social que oportuniza nova maneira de entender o fenômeno "ouvir vozes" e de como conviver com elas, além de apoiar outras pessoas através dos relatos de suas próprias experiências.

O diálogo mantido entre os usuários do grupo permite um novo entendimento sobre suas vivências, propiciando que os mesmos possam encontrar seus próprios caminhos para recuperar a condução de suas vidas. Essa interação envolve a aceitação e o reconhecimento dos limites, medos, angústia e solidão que surgem em consequência da audição de vozes, sem a pretensão de suprimir as vozes, mas de vivenciá-las em outra perspectiva, permitindo ao ouvidor assumir o controle na sua relação com elas. 
Durante a pesquisa, observamos 793 postagens na Intervoice: The International

Hearing Voices (https://www.facebook.com/groups/intervoice) - grupo da Intervoice no Facebook sobre diversos assuntos com conteúdos variados, como artigos sobre doenças mentais, tratamentos e medicamentos. Desse total, 18 postagens tratam especificamente da experiência de ouvir vozes em suas diversas perspectivas. São estas que nos interessam, visto que a partir da interação entre os ouvidores de vozes (postagens e respectivos comentários) é que encontramos nosso efetivo material para análise, já que estamos buscando exemplares de estratégias de ajuda e/ou suporte mútuos no ambiente virtual.

Os critérios de seleçâo utilizados foram: os posts que continham mais interaçôes; os posts que apontassem o desenvolvimento de estratégias que promovessem a mudança a partir da partilha de experiências; os posts que levassem à construção da estratégia de ajuda mútua, ampliando a compreensão das diversas expressões da questão da audição de vozes, possibilitando que as pessoas pudessem se empoderar a partir das informações adquiridas. Após a apresentação dos trechos recortados, com posts e comentários referentes a cada postagem, fizemos uma análise minuciosa dos discursos, procurando identificar, sobretudo, como se dá o processo de ajuda mútua no ambiente virtual.

Optamos por omitir os nomes dos usuários, adotando o uso de suas iniciais para sua identificaçáo. Finalmente, agrupamos as postagens e comentários por temas. Vale ressaltar que os textos originais estão em inglês e que a tradução para o português é de nossa autoria.

\section{Resultados e Discussão}

\section{Trocas de experiências virtuais no Intervoice}

Nos posts, observamos diálogos de usuários que vivenciam a experiência da audição de vozes. Durante nove meses de observação das mídias sociais da Intervoice, verificamos que ficou explícito nas narrativas o impacto da experiência de ouvir vozes, o efeito perturbador por serem vozes hostis e controladoras, não só para aqueles que as ouvem, como também para amigos e familiares. Nesta seção de resultados e análise, procuramos investigar como alguns ouvidores vivenciam suas experiências. Decidimos agrupar as postagens e comentários semelhantes em seu conteúdo, para entendermos como se processava a troca de experiências entre esses usuários e seu entendimento sobre medicação, audição de vozes e 
quais abordagens estariam mais evidenciadas. Para isso, agrupamos as narrativas em temas separados, e as elencamos como as seguintes categorias:

- Medicação: experiências sobre os benefícios e as críticas, que aborda o uso da medicação psiquiátrica na perspectiva dos ouvidores de vozes.

- Vozes criticas e negativas: aprendendo a conviver com a experiência, que trata da troca informaçôes e aconselhamentos na busca de estratégias que possibilitem amenizar as angústias desencadeadas pelo impacto subjetivo dessas vozes.

- Amigos elou familiares: tecendo caminhos para o acolbimento, onde nos deparamos com a experiência de familiares e/ou amigos que buscam conhecimentos de outras experiências e procuram oportunidades de participação e aprendizagem.

- Sobre a dificuldade de aceitaçâo dos familiares: reinventando as relaçóes, onde observamos que é importante que os familiares aceitem a existência das vozes para oferecerem o apoio necessário

- Troca de experiência em tempo real: um pedido de socorro imediato, onde observamos a ajuda que um usuário obteve no momento da "crise", recebendo algumas orientaçóes sobre como lidar com a situação, que parecia bastante assustadora.

- Ressignificando a experiência e o benefício das vozes, onde ressaltamos que algumas pessoas conseguem reconhecer aspectos mais agradáveis do fenômeno, e que sob esta perspectiva a atitude perante as vozes muda significativamente.

- Mecanismos explicativos: uma forma interessante de explicar a audiçáo de vozes em formas criativas de superaçáo, onde encontramos outras formas de entender a experiência, como telepatia e hipnose das vozes, indicando criatividade e superação.

\section{Medicação: experiências sobre os benefícios e as críticas}

Post de 27 de maio de 2015: “[...] Eu sou membro desse grupo há muito tempo, mas essa é a primeira vez que eu posto. Alguém aqui também mantém suas vozes sob controle ou não é tấo comum com medicamentos como acontece comigo?” T.R.

Este post gerou uma interação entre o autor e outros participantes. Na interação com um dos usuários, que identificaremos como W.M., obteve-se o seguinte comentário: “T.R., você foi ordenado a tomar os medicamentos? Alguém foi na sua casa e aplicou as injeçôes? Tomar medicamentos faz parte de sua rotina?" 
Outro comentário, elaborado por D.D., faz referência ao Intervoice: "Eu amo

a Intervoice, tenho lido muita informação interessante desde que eu encontrei esse grupo." Esse debate permitiu ao autor, além de interagir com seus pares, conhecer outros recursos como o grupo de ajuda mútua de ouvidores de vozes.

Com o objetivo de informar, o site Intervoice disponibiliza um manual (http:// www.intervoiceonline.org/support-recovery/thinking-about-medication) que reúne informaçóes sobre medicamentos psiquiátricos, subsidiando a decisão dos ouvidores de vozes sobre o uso ou não da medicação, pesando as vantagens e desvantagens.

\section{Vozes críticas e negativas: aprendendo a conviver com a experiência}

Post de 26 de setembro de 2014: “[...] Vocês têm alguma sugestão sobre como lidar com essas vozes negativas, elas estấo me chateando muito, aprecio seus conselhos.” J.G.

Este post teve 15 comentários, sugerindo estratégias de se relacionar com as vozes. Destacamos os comentários de S.J. ("A Intervoice aconselha que é melhor se relacionar com as vozes do que estar em constante guerra com elas. Se você tem pensamentos associados ao suicídio, procure ajuda”) e de M.R. (“Compaixão e bondade consigo mesmo podem ajudar a curar ao longo do tempo. Eu espero que você tenha alguém em sua vida com quem você possa conversar sobre o que está acontecendo no momento").

Paul Baker, em seu manual Abordagem de ouvir vozes, afirma que para se chegar a um acordo com as vozes, é necessária alguma forma de aceitação; o autor define as estratégias utilizadas pelos ouvidores de vozes, que objetivam maneiras de controlar ou lidar com as vozes (BAKER, 2015).

Nas narrativas, percebemos a potência da internet na comunicação entre pares e a circulação do conhecimento experiencial. Esse grupo demonstra que a internet maximiza o processo de ajuda mútua online, que acontece em tempo real, sem dias e horários fixos, reunindo pessoas de diferentes faixas etárias, situação socioeconômica, mas que têm em comum a questão da audição de vozes.

\section{Amigos e/ou familiares: tecendo caminhos para o acolhimento}

Post de 28 de abril 2015: "Olá pessoal, meu pai quer ser capaz de conversar com outras pessoas que ouvem vozes. Ele me pediu para perguntar nesse grupo se alguém já ouviu a voz de J e quer que eu pergunte se alguém sabe quem é?” K.K. 
Este post teve sete comentários, dos quais destacamos dois: J.C. ("Eu acredito que ele esteja tentando entender se são reais ou não. Além disso não são pessoas, são aliens inteligentes") e K.K. ("Os nomes que as vozes assumem podem ser muito aleatórios, e eles podem frequentemente assumir o som e a personalidade de pessoas que você realmente conhece. A real questão é que as vozes podem estar confundindo ou deixando-o aflito").

É interessante perceber que este post atribui identidades específicas às vozes, inclusive dando-lhes nome, entendendo-as como reais, existentes, e como tal podem ser conhecidas e/ou reconhecidas por outras pessoas, contudo ninguém pode vê-las, são intangíveis. Segundo Romme e Escher (1997), quando a voz tem uma identidade concreta e estável, pode anunciá-la ao ouvidor ou então é o ouvidor que nela reconhece uma pessoa específica, por isso não é de estranhar que tentem descobrir uma razão ou interpretação que explique essa experiência tão peculiar.

\section{Sobre a dificuldade de aceitação dos familiares: reinventando as relaçóes}

Post de 15 de março de 2015: “... Minha mãe fica cada vez mais submersa em ideias absurdas..." S.V.

Este post suscitou 24 comentários, entre os quais destacamos dois que demonstram como se processa a possibilidade de ajuda mútua no ambiente virtual: L.B. ("Eu sou da Bélgica e aprendi sobre um método inovador que ajuda muito, o Diálogo Aberto, se você quiser saber mais, me contacte), e de K.A. ("Você está no lugar certo para ter apoio. Você olhou no site da Intervoice para ter mais informaçóes sobre o que você está fazendo e para onde ir? Você pode encontrar um grupo local de ouvidores de vozes para a sua mãe frequentar? Eu achei o grupo Intervoice online. Boa sorte!").

Para Baker (2015), a maioria das pessoas que vivem bem com suas vozes tem familiares que oferecem suporte e aceitam a experiência. Por isso, sugere um plano de açáo sobre como se relacionar como um membro/amigo da família que ouve vozes.

\section{Troca de experiências em tempo real: um pedido de socorro imediato}

Post de 28 de fevereiro de 2015: "Comecei a ver sombras de pessoas e figuras, não quis acordar minha namorada porque me sinto estúpido, estou muito paranoico.” D.R. 
Este post teve dois comentários: K.H. (“Olá, parece assustador e exaustivo ter essas experiências sozinho à noite. Não se sinta estúpido, talvez você deva acordar sua namorada e perguntar a ela o que vê no quarto, tente acreditar no que ela disser. Às vezes, é mais fácil ficar calmo quando tem alguém para te confortar") e R.C. ("Tente comparar o que você vê com um olho... vá alternando entre o bom e o ruim... se encontrar diferença ao alternar os olhos...isso pode ajudar").

Nesta postagem, o usuário relata em tempo real uma experiência vivida como assustadora, uma associação de ansiedade e medo. No meio da crise, ele decide buscar ajuda virtual para não alarmar sua companhia real. Imediatamente recebe duas respostas tentando acalmá-lo.

\section{Ressignificando a experiência e o benefício das vozes}

Post de 29 de dezembro de 2014: “... As vozes podem ser protetoras...” J.R.

Este post teve quatro comentários que relatam que o melhor é entender as vozes ao invés de demonizá-las e sugerem uma negociação com as vozes. Elencamos dois: D.U. ("As vozes geralmente são protetivas... Dessa forma, ao invés de demonizar e tentar eliminá-las, seu trabalho passa a ser entendê-las"), e de J.M. ("Eu também me tornei mais independente e determinada por causa delas. Elas realmente me ajudaram a me tornar uma pessoa adulta menos dependente...e me ajudou a criar meu senso de identidade...”).

Nesta postagem, percebemos que a aceitação das vozes é de extrema importância para o crescimento pessoal, assim como é importante falar sobre as vozes. É possível aprender e reconhecer aspectos mais agradáveis do fenômeno, já que sob esta perspectiva, a atitude perante as vozes muda significativamente.

\section{Mecanismos explicativos: uma forma interessante de explicar a audição de vozes em formas criativas de superaçáo}

Post de 2 de maio de 2015: "Alguém mais acredita que ouvir vozes é telepatia ou apenas eu?" S.T.

Este post teve cinco comentários. Destacamos um: D.M. ("Eu não. Minhas vozes nunca disseram nada que me fizessem acreditar que era telepatia. Desculpe por não apoiar a ideia de telepatia"). 
Esta postagem teve quatro comentários, destacando a hipnose como estratégia para superar a relação de comando das vozes. Destacamos um: C.H. (“É uma brilhante ideia!").

As técnicas desenvolvidas para ajudar a lidar com a audição de vozes se concentram na experiência individual e enfatizam que a aceitação é crucial, requer que o ouvidor de voz crie espaço para as vozes, não para segui-las, mas para aprender a controlá-las. É muito importante relacionar as vozes com a história de vida do ouvidor, a fim de compreender as questôes emocionais.

\section{Considerações finais}

O presente artigo demonstra, a partir das observaçôes, que as mídias sociais configuram uma nova maneira de aproximar pessoas isoladas por algum sofrimento físico e/ou psíquico, incentivando-as a manter contato com seus pares e se incluírem no mundo. Esse contato no mundo virtual permite ao narrador a construção e/ou reconstrução de sua história, como também uma reafirmação de sua identidade social.

Contar a própria história ou de outras pessoas é um meio de criar diálogos, promover autoconhecimento e permitir o compartilhamento de experiências atravessadas por traumas, medos, dúvidas de pessoas que enfrentam uma situação dramática. Construir histórias através do compartilhamento com seus pares pode contribuir na construção de uma história coletiva.

Serpa Júnior (2011) afirma que, na prática dos cuidados, é preciso tomar as construçóes narrativas e culturais como parte integrante do trabalho clínico, entendendo que o sentido de um processo de adoecimento náo se esgota no conhecimento biomédico. Muñoz et al. (2011) afirmam que as narrativas têm sido tomadas, no campo da Saúde Mental, como forma privilegiada de acessar o ponto de vista das pessoas que vivem a experiência da psicose. Relatam que no universo da pesquisa científica, existe uma tendência a desconsiderar, ou pelo menos minimizar, os relatos pessoais sobre o adoecimento psíquico. Baseamonos na Medicina Narrativa, que é uma prática clínica orientada pela busca de sabermos o que fazer com as histórias. Não substitui nada daquilo que os clínicos fazem, mas é fortalecida pela compreensão das consequências que têm as histórias que nos são contadas (CHARON et al., 2017). 
Baseados no modo subjuntivo da narrativa (BRUNER, 1990) que nos permite perceber a produção de um efeito em quem conta e em quem ouve uma história, identificamos que cada indivíduo traz a sua narrativa construindo novas, e convida outros a serem narradores de suas histórias, construindo uma relação entre o que narra e o que ouve.

A partir dos posts, percebemos que o avanço das tecnologias no ambiente virtual mudou a concepção dos grupos de ajuda mútua. A interatividade estabelece laços sociais entre os indivíduos online, através das interaçôes on time.

Quando, em 2009, o grupo Intervoice no Facebook foi criado, possibilitou uma experiência diferenciada aos ouvidores de vozes interessados no compartilhamento de experiências, de forma a criar estratégias tanto de entendimento do fenômeno ouvir vozes, quanto na maneira de conviver com elas. Percebemos que, através da interatividade neste ambiente, a troca de experiências e de apoio proporciona aos ouvidores de vozes, bem como a seus familiares, caminhos que os levam ao sentimento de pertencimento, a organizar mecanismos e formas de lidar com a experiência de ouvir vozes. $\mathrm{O}$ alcance das mídias sociais nos permite entender a influência que estas exercem no modo como as pessoas se comunicam, interagem e compartilham conhecimento.

A experiência de ouvir vozes pode ser dolorosa, perturbadora ou até mesmo desesperadora para quem vivencia, podendo levar ao isolamento e tornar a vivência do processo muito solitária. Estabelecer estratégias de apoio e acolhimento a pessoas que sofrem com a audição de vozes é contribuir com a ruptura de paradigmas que envolvem a questão da loucura, e cooperar para a transformação do olhar da sociedade em relaçáo ao fenômeno do ouvir vozes (MUNÓZ et al., 2011).

No decorrer da pesquisa, foi possível entender que o ambiente virtual possibilita democratizar o alcance e amplia a resolutividade das situaçóes vivenciadas. Um ambiente de interação, de intercâmbio de conhecimentos, que, ao permitir o compartilhamento de experiências, assume diferentes configuraçóes conforme as articulaçóes, as associaçóes e as conexóes estabelecidas. Os resultados sugerem que o processo de ajuda mútua entre os membros do grupo Intervoice do Facebook ocorre nas trocas de mensagens entre os usuários do grupo, seja compartilhando suas experiências pessoais, seja comentando interativamente o que foi compartilhado. 

acontece em diversos países, ultrapassando barreiras físicas e geográficas, privilegiando o processo de interação, ampliando o acesso às informaçôes e utilizando várias estratégias que visam amenizar o sofrimento dos que ouvem vozes. Os países que mais apareceram nos perfis foram Inglaterra, Estados Unidos, Irlanda, Escócia, Canadá, Holanda e Nigéria, num total de 34 pessoas interagindo no grupo escolhido para a pesquisa. Segundo Lévy (1999, p.127), "[u]ma comunidade virtual é construída sobre as afinidades de interesses, de conhecimentos, sobre projetos mútuos, em um processo de cooperação ou de troca, tudo isso independentemente das proximidades geográficas e das filiaçôes institucionais".

O que nos pareceu mais evidente na análise das postagens e na interação entre os internautas membros do grupo é que os relatos de suas vivências, a troca de conhecimentos e informaçōes e o compartilhamento das angústias, mobilizaram cada participante do grupo na busca de novas informaçóes e conhecimentos para serem divididos e discutidos entre seus pares, na perspectiva de buscar novas estratégias para minimizar o sofrimento psíquico.

Em termos gerais, as questóes envolvem preocupações quanto à dificuldade de lidar com a experiência, discriminação e exclusão, pois buscam oferecer apoio a todas as pessoas que ouvem vozes e desconstruir a relaçáo ouvir vozes com alguma etiqueta diagnóstica a fim de reduzir o estigma na sociedade. A interação dos ouvidores de vozes nas mídias sociais, especificamente no grupo Intervoice do Facebook, possibilitam aos ouvidores de vozes aprenderem a lidar com suas vozes e encontrar uma espécie de equilíbrio.

As redes sociais, definidas como teias de relaçóes que circundam o indivíduo, permitem que ocorram união, comutação, trocae transformação. Ao integrá-la, existe a possibilidade de se organizar socialmente como uma estrutura descentralizada, em que todos podem, simultaneamente, ocupar diferentes e distintas posiçóes, dependendo dos interesses e dos temas tratados. A aprendizagem, nas redes, é desenvolvida em grupo, de modo a fortalecer os vínculos entre seus componentes e, sobretudo, ampliar o poder de decisão dos vários nós que as constituem. As redes possibilitam organizar as comunidades a fim de buscar melhorias nas condiçóes de suas vidas, que podem ser concretizadas na perspectiva de promover apoio social e compartilhamento de experiências que podem dar importante contribuição no processo de construção de grupos de ajuda mútua. 
A internet favorece ainda o desenvolvimento da autonomia dos usuários, dando características de auto-organização, que os leva a constituir práticas coletivas, criando uma coesão entre eles, construindo novas realidades e produzindo algo que não existia antes. Com o empoderamento por meio das informaçóes adquiridas, tornam-se sujeitos atuantes, questionadores e reflexivos, encorajados a fomentar o debate sobre suas vivências. Nesse universo, o aparecimento das narrativas compartilhadas se lança numa conversaçáo agrupada com a consciência que estão a participar de uma história única, porém múltipla. A narrativa compartilhada é sempre permeada de histórias paralelas que se alastram no ciberespaço (MALINI, 2010).

Segundo Melca et al. (2014), os usuários das mídias sociais, ao escreverem seus posts, compartilham uma semente de uma ideia que atrairá outros usuários, que em seguida, colaborativamente desenvolvem essas ideias e até as modificam, criando algo novo, construindo uma estrutura de ideias interconectadas. Portanto, a interação dos usuários no grupo pode ser um exemplo de como a interatividade no ambiente virtual propicia não apenas o compartilhamento de conhecimentos sobre ouvir vozes, mas também cria grupos de apoio e solidariedade, construído

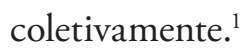

\section{Referências}

BAKER, P. Abordagens de ouvir vozes: treinamento no Brasil. São Paulo: CENAT, 2015.

BOORKMAN, T. Introduction to Special Issue. American Journal of Community Psychology, v. 19, n. 5, p. 643-650, 1991.

BRAGA, A. Técnica etnográfica aplicada à comunicação online: uma discussão metodológica. UNIrevista, vol. 1, n 3, julho 2006.

BRUNER, J. S. Acts of meaning. Cambridge, MA: Harvard University Press, 1990.

CHARON, R. et al. The principles and practice of narrative medicine. New York: Oxford University Press, 2017.

COLEMAN, R. Recovery: an alien concept? United Kingdom: Handsell Publications, 2011.

CORSTENS, D.; ESCHER, S.; ROMME, M. Accepting and working with voices: the Maastricht Approach. In: MOSKOWITZ, A.; SCHAFER, I.; DORAHY, M. J. (Eds.). Psychosis, trauma and dissociation: emerging perspectives on severe psychopathology. Oxford, UK: Wiley-Blackwell, 2008. p. 319-331.

CRUZ, D. I., PAULO, R. R. D., DIAS, W. S., MARTINS, V. F., GANDOLFI, P. E. O uso das mídias digitais na educaşão em saúde. Cadernos da FUCAMP, v.10, n.13, p.106-129/2011. 

Alegre: Sulina, 2011.

FRANCO, A. FLUZZ Série Completa, 2013. Disponível em: <http://pt.slideshare.net/ augustodefranco/fluzz-srie-completa>. Acesso em: 15 out. 2016.

O poder nas redes sociais, 2009b. Disponível em: <http://pt.slideshare.net/ augustodefranco/o-poder-nas-redes-sociais-2a-versao >. Acesso em: 12 jan. 2016. . Redes são ambientes de interação, não de participação. Slideshare, 2009. Disponível em: <http://www.slideshare.net/augustodefranco/redes-so-ambientes-de-interao-no-departicipao>. Acesso em: 15 out. 2016.

HINE, C. A etnografia virtual. London: Sabio, 2000.

- Virtual methods and the sociology of cyber-social-scientific knowledge. In: . (org). Virtual Methods. Issues in social research on the internet. Oxford: Berg. 2005. Disponível em: <http://cyberlabnau.files.wordpress.com/2012/11/hine-c-virtualmethods.pdf>. Acesso em: 15 out. 2016.

KOZINETS, R. V. Netnography 2.0. In: BELK, R. W. Handbook of qualitative research methods in marketing. London: Edward Elgar Publishing, 2007.

. The field behind the screen: using netnography for marketing research in on line communities. Journal of Marketing Research, v. 39, 2002. Disponível em: <http://www.nyu. edu/classes/bkg/methods/netnography.pdf> Acesso em: 15 out. 2016.

. Cibercultura. São Paulo. Editora 34, 1999.

MALINI, F. Princípios inconstantes. São Paulo. Itaú Cultural, 2010.

MELCA, F. M. A. et al. Ambientes de Nuvem para Pesquisa e Educação: o caso do NEXT. In: ENANCIB, Minas Gerais, 2014. Disponível em: <http://www.next.wiki.br/repositorio/ content/111>. Acesso em: 15 out. 2016.

MUÑOZ, N. M. et al. Pesquisa clínica em saúde mental: o ponto de vista dos usuários sobre a experiência de ouvir vozes. Estudos de Psicologia, v. 16, n. 1, p. 83-89, jan-abr 2011. Disponível em: <http://www.scielo.br/pdf/epsic/v16n1/a11v16n1.pdf>. Acesso em: 15 out. 2016.

NEWTON, G. Self-help groups. Can they help? Journal of Psychosocial Nursing, 22. 1984

PEIXOTO, M. M.; HEILBORN, M. L. Mulheres que amam demais: conjugalidades e narrativas de experiência de sofrimento. Estudos Feministas, Florianópolis, v. 24, n. 1, p. 406, jan-abr 2016. Disponível em: <http://www.scielo.br/pdf/ref/v24n1/1805-9584ref-24-01-00045.pdf>. Acesso em: 15 out. 2016.

PRESOTTO R. F. Participação de Usuários de Serviços de Saúde Mental em Pesquisas: Um Olhar a partir dos conceitos de Empowerment e Recovery, 2013, 151f. Dissertação. Faculdade de Ciências Médicas, Unicamp, Campinas, 2013. 
RAPPAPORT, J. Desinstitucionalização: Empowerment e interajuda. O papel dos técnicos de saúde mental no século XXI. Análise Psicológica, v. 8, n. 2, p. 143-162, 1990.

RECUERO, R. Redes sociais na internet. Porto Alegre: Sulina, 2009.

ROMME, M.; ESCHER, S. Hearing voices. Schizophrenia Bulletin, v. 15, n. 2, p. 209216, 1997.

SEIKKULA, J., \& OLSON, M. The Open Dialogue Aproach Acute. Family process. Wiley Online Library, 2003.

SERPA JR., O.D. Alucinação auditiva verbal como alteração da autoconsciência - aspectos históricos. In RODRIGUES, A.C.T., STREB, L.G., DAKER, M.V. e SERPA JR., O.D. (orgs.) Psicopatologia conceitual. São Paulo: Roca, 2013, pp. 17-29.

. O papel da psiquiatria na reforma psiquiátrica. Ciência da Saúde Coletiva, 16 (12): 4675-4683, 2011.

SILVA, J. B. B. Quando amar é um "problema": significados de amar demais a partir do $M A D A$. Monografia apresentada para a obtenção do título de bacharel em Ciências Sociais, Universidade Federal do Rio Grande do Sul, Porto Alegre, 2008.

STONE, H., STONE, S., Embracing Our Selves: The Voice Dialogue Manual. Nataraj Publishing, 1993.

TURKLE, S. La vida en pantalla: la identidad en la era de internet. Barcelona: Paidós, 1997. VASCONCELOS, E. M. (coord.) Cartilha [de] ajuda e suporte mútuos em saúde mental: para participantes de grupos. Rio de Janeiro : Escola do Serviço Social da UFRJ; Brasília: Ministério da Saúde, Fundo Nacional de Saúde, 2013. Disponível em: <http://www. abrasme.org.br/arquivo/download?ID_ARQUIVO=4002> Acesso em: 15 out. 2016.

\section{Nota}

O. C. Barros participou da elaboração do projeto de pesquisa, construção e organização do campo empírico, análise e interpretação dos dados, redação e revisão da versão final do artigo. O. D. Serpa Jr orientou o projeto de pesquisa, a construçáo e organizaçáo do campo empírico, a análise e interpretação dos dados, participou da redação e da revisão do artigo. 


\section{Abstract}

\section{Hearing voices: a netnographic study of virtual environments for peer suport}

The reflection focus of this article is the formation of a social network through an internet social media, the Intervoice, seeking to understand how social networks integrate in offerings of peer support. By choosing the experiences lived by voice hearers on Intervoice's virtual environments as the main axis of our approach, we seek to identify the existence of a change of perspective in relation to the exclusively descriptive approaches by voice hearers, as well as analyzing if this social media, whilst broadening the possibility of interaction and sharing of experiences, favors the process of peer support for people that hear voices. A methodology was developed from the observation of the Intervoice posts on Facebook from September 2014 to May 2015. After thorough analysis, we concluded that Facebook was the media with most interactions when compared with other media such as Twitter and YouTube. Thus, we selected the most interesting posts and comments and pointed out issues and specific discussions, particularly those that dealt with peer support. The results of this research point to the extreme relevance that the peer support through virtual environments and social networks has been gaining in recent times, mainly by the possibility of real time interaction.

> Keywords: voice hearers, peer support, social media and networks. 